\title{
Effects of Chronic Antagonism of Endocannabinoid-1 Receptors on Glucose Tolerance and Insulin Action in Skeletal Muscles of Lean and Obese Zucker Rats
}

\author{
Katherine A. Lindborg ${ }^{a}$ Stephan Jacob ${ }^{b}$ Erik J. Henriksen ${ }^{a}$ \\ ${ }^{a}$ Muscle Metabolism Laboratory, Department of Physiology, University of Arizona College of \\ Medicine, Tucson, Ariz., USA; ${ }^{b}$ Cardiometabolic Institute, Villingen-Schwenningen, Germany
}

\author{
Key Words \\ CB1 receptor · Insulin resistance $\cdot$ Soleus muscle $\cdot$ SR141716 $\cdot$ Zucker rat
}

\begin{abstract}
Background/Aims: Antagonism of the endocannabinoid receptor-1 (CB1R) directly improves whole-body metabolic parameters of insulin resistance. The present investigation determined the effects of chronic CB1R antagonism on whole-body and skeletal-muscle insulin action in insulin-sensitive lean and insulin-resistant obese Zucker rats. Methods: Animals were either fed ad libitum or in pairs, or treated with SR141716 (10 mg/kg i.p. for 14 days). Results: Food intake was significantly reduced $(p<0.05)$ after initial SR141716 treatment and remained decreased in both lean and obese animals until day 13 . Fasting plasma glucose decreased (24\%) and insulin increased (43\%) in lean SR141716-treated (24\%) rats compared to lean ad libitum-fed controls, but not in the corresponding obese groups. Fasting plasma free fatty acids were reduced by CB1R antagonism in lean (21\%) and obese (42\%) animals. Whole-body insulin sensitivity was increased (36\%) in obese SR141716-treated rats compared to obese ad libitum-fed controls, which was associated with reduced insulin secretion during an oral glucose tolerance test. Insulinstimulated glucose transport activity in the soleus was greatest in the respective SR141716treated lean and obese groups compared to the corresponding ad libitum- and pair-fed controls. Chronic SR141716 treatment did not induce alterations in signaling factors associated with the regulation of glucose transport [protein kinase B (Akt), glycogen synthase kinase-3ß, $5^{\prime}$-AMP-dependent protein kinase, or p38 mitogen-activated protein kinase] in the soleus.
\end{abstract}




\section{CardioRenal Medicine}

\begin{tabular}{l|l}
\hline Cardiorenal Med 2011;1:31-44 \\
\hline $\begin{array}{l}\text { DOI: 10.1159/000322826 } \\
\text { Published online: January 17, } 2011\end{array}$ & $\begin{array}{l}\text { ○ } 2011 \text { S. Karger AG, Basel } \\
\text { www.karger.com/crm }\end{array}$ \\
\hline
\end{tabular}

Lindborg et al.: Chronic CB1R Antagonism and Insulin Action

Conclusions: These results indicate that, while the chronic treatment with CB1R antagonism markedly diminished food intake in lean and obese Zucker rats, there are also significant metabolic improvements in whole-body and skeletal-muscle insulin action mediated by CB1R antagonism through mechanisms independent of reduced caloric intake.

Copyright $\odot 2011$ S. Karger AG, Basel

\section{Introduction}

The endocannabinoid system is a potentially novel pharmacological target in treating components of the metabolic syndrome [1]. Cannabinoid receptor-1 (CB1R) antagonists were originally developed and utilized as appetite suppressants and in the treatment of obesity. Recently, however, CB1R antagonists have been shown to elicit beneficial effects on metabolic parameters beyond those attributed to decreased food intake and weight loss alone [2-4]. In rodent models, selective CB1R antagonism or knockout of CB1R causes anorexic behaviors, leading to reductions in food intake and body weight [5-7] associated with reduced visceral adiposity [8]. In animals treated with the CB1R antagonist SR141716, the reduction in food intake was transient, but caused a long-term reduction in body weight, possibly related to elevated energy expenditure induced by CB1R antagonism [2, 9].

Previous studies have also shown that the endocannabinoid system is involved in the regulation of glucose tolerance and whole-body insulin sensitivity. Acute CB1R agonism in male Wistar rats caused reduced glucose tolerance, whereas acute CB1R antagonism was associated with enhanced glucose tolerance [10]. Moreover, chronic CB1R antagonism improved insulin sensitivity in rats with diet-induced obesity compared to pair-fed and ad libitum-fed controls [11]. Finally, chronic rimonabant treatment of male obese Zucker rats reduced glucose-stimulated insulin secretion, whereas glucose tolerance was unchanged during an oral glucose tolerance test (OGTT) [12]. Chronic CB1R antagonism may improve glucose tolerance through an increased insulin-mediated glucose transport in skeletal muscles, as a 7-day treatment with the CB1R antagonist SR141716 led to increased in vitro insulin stimulation of glucose transport activity in the soleus muscle of leptin-deficient obese mice [9]. However, no study to date has simultaneously assessed the chronic effects of CB1R antagonism on glucose tolerance, whole-body insulin sensitivity, and insulin action in skeletal muscles in a rat model of the metabolic syndrome and pre-diabetes, such as the obese Zucker rat.

The impact of chronic CB1R antagonism on circulating lipids and tissue lipid storage has recently been investigated. Chronic SR 141716 treatment reduced circulating triglycerides in rats fed a high-fat diet [11, 13] and in obese patients [14]. However, reports on the effect of chronic CB1R antagonism on fasting plasma free fatty acid (FFA) levels are conflicting. One investigative group [11] found no effect of chronic SR141716 treatment on FFA levels in rats fed a high-fat diet, while there was a significant decrease in fasting plasma FFA after chronic SR141716 treatment in obese Zucker rats [15] and mice with diet-induced obesity [16]. Moreover, chronic SR141716 treatment (21 days) of rats with diet-induced obesity was associated with a significant increase in hepatic triglyceride storage [11], while 28 days of SR141716 treatment led to a small and statistically insignificant decrease in liver triglycerides [13]. Triglyceride storage in skeletal muscles was also assessed in this latter investigation, with varying effects of SR141716 treatment depending on the muscle type studied [13].

In the context of the foregoing information, the purpose of the present study was to determine the effects of chronic CB1R antagonism (using SR141716) on body weight, visceral fat, glucose tolerance, whole-body insulin sensitivity, and skeletal-muscle glucose transport, and the involvement of associated signaling factors and plasma FFA in both insulin-sensi- 


\section{CardioRenal Medicine}

\begin{tabular}{l|l}
\hline \multicolumn{2}{l}{ Cardiorenal Med 2011;1:31-44 } \\
\hline $\begin{array}{l}\text { DOI: 10.1159/000322826 } \\
\text { Published online: January 17, } 2011\end{array}$ & $\begin{array}{l}\text { @ 2011 S. Karger AG, Basel } \\
\text { www.karger.com/crm }\end{array}$ \\
\hline
\end{tabular}

tive, lean Zucker rats and insulin-resistant, obese Zucker rats. Moreover, we also assessed the impact of a single dose of SR141716 on glucose tolerance, whole-body insulin sensitivity, and skeletal-muscle glucose transport activity.

\section{Methods}

Animals and Treatments with SR141716

Female lean ( $F a /-)$ and obese ( $f a / f a)$ Zucker rats were obtained from Harlan (Indianapolis, Ind., USA). Treatment began at 9-10 weeks of age, at which time the lean animals weighed 150-170 $\mathrm{g}$ and the obese animals weighed $290-330 \mathrm{~g}$. Animals were housed in pairs in a temperature-controlled $\left(20-22^{\circ} \mathrm{C}\right)$ room with a 12:12 h light-dark cycle (lights on from 7 a.m. to 7 p.m.) at the Central Animal Facility of the University of Arizona. Ad libitum-fed and SR141716-treated animals had free access to chow (diet No. 7001; Teklad, Madison, Wisc., USA) and water. Pair-fed control animal group treatments were staggered 1 day after starting the SR141716-treated group, and this group was fed the average amount of chow consumed by the SR141716-treated group. All procedures were approved by the Institutional Animal Care and Use Committee at the University of Arizona.

Animals were separated into three groups of 4 animals for both lean and obese groups. Each group was then matched for weight at the start of the respective treatments $(160 \pm 2 \mathrm{~g}$ for lean and $301 \pm 2 \mathrm{~g}$ for obese groups). Animals were treated intraperitoneally with either $10 \mathrm{mg} / \mathrm{kg}$ SR 141716 or vehicle (20\% Tween 80 and $0.9 \% \mathrm{NaCl})$. Animal weights and 24 -hour food consumption were measured at the same time daily ( $\sim 9$ a.m.) for 14 days. SR141716 was pulverized and the powdered compound was mixed fresh daily with $20 \%$ Tween 80 and $0.9 \% \mathrm{NaCl}$ into a slurry of $0.5-\mathrm{ml}$ doses, with each dose providing $10 \mathrm{mg} / \mathrm{kg}$ active ingredient per animal. In the acute treatment study, animals were treated a single time with $10 \mathrm{mg} /$ $\mathrm{kg}$ SR141716, and $2 \mathrm{~h}$ later they underwent an OGTT or, at least 5 days later following another acute dosing, an OGTT was used to assess soleus muscle glucose transport activity (see below).

\section{Oral Glucose Tolerance Tests}

On the 11th day of treatment, animals were food restricted overnight (chow was restricted to $4 \mathrm{~g}$ at $5 \mathrm{p}$.m. and was consumed immediately). Animals were subjected to an OGTT using $1 \mathrm{~g} / \mathrm{kg}$ glucose feeding by gavage. Blood $(\sim 0.25 \mathrm{ml})$ was collected from a tail snip at time $0 \mathrm{~min}$ (immediately before gavage), and $15,30,60$, and $120 \mathrm{~min}$ after glucose administration. Whole blood was vortexed with EDTA (18 mmol/l final concentration) and then centrifuged at $13,000 \mathrm{~g}$ for $30 \mathrm{~s}$ to isolate the plasma. Plasma was removed and stored at $-80^{\circ} \mathrm{C}$ until analysis. Following blood collection, animals were provided $2.5 \mathrm{ml}$ of $0.9 \%$ saline solution by subcutaneous injection to compensate for plasma loss during the OGTT. Plasma was analyzed for glucose (Thermo Electron, Pittsburgh, Pa., USA), insulin (Linco Research, St. Charles, Mo., USA), and FFA (basal sample only; Wako, Richmond, Va., USA).

\section{Determination of Muscle Glucose Transport Activity}

Animals were treated a final time on day $14,24 \mathrm{~h}$ prior to incubation. After an overnight food restriction (4 g at $5 \mathrm{p}$.m. as before), animals were deeply anesthetized at $8 \mathrm{a}$.m. with pentobarbital sodium (50 $\mathrm{mg} / \mathrm{kg}$ i.p.), and strips (25-35 mg) of one of the soleus muscles from each animal were prepared for in vitro incubation in the unmounted state. Muscles were incubated for $60 \mathrm{~min}$ at $37^{\circ} \mathrm{C}$ in $3 \mathrm{ml}$ of oxygenated $\left(95 \% \mathrm{O}_{2}, 5 \% \mathrm{CO}_{2}\right)$ Krebs-Henseleit buffer (KHB) containing $8 \mathrm{mmol} / \mathrm{l}$ glucose, $32 \mathrm{mmol} / \mathrm{l} \mathrm{mannitol}$, and $0.1 \%$ BSA (RIA grade; Sigma Chemical, St. Louis, Mo., USA), in the absence or presence of $5 \mathrm{mU} / \mathrm{ml}$ insulin (Humulin R; Lilly, Indianapolis, Ind., USA). The incubated muscles were rinsed in $3 \mathrm{ml}$ of oxygenated $\mathrm{KHB}$ containing $40 \mathrm{mmol} / \mathrm{l}$ mannitol, $0.1 \% \mathrm{BSA}$, and insulin (if previously present) for $10 \mathrm{~min}$ at $37^{\circ} \mathrm{C}$. After rinsing, the muscles were transferred to $2 \mathrm{ml}$ of KHB containing $1 \mathrm{mmol} / 12$-deoxy- $\left[1,2-{ }^{3} \mathrm{H}\right]-$ glucose $\left(300 \mu \mathrm{Ci} / \mathrm{mmol}\right.$; Sigma Chemical), $39 \mathrm{mmol} / 1$ [U-1 $\left.{ }^{14} \mathrm{C}\right]$ mannitol $(0.8 \mu \mathrm{Ci} / \mathrm{mmol}$; ICN Radiochemicals, Irvine, Calif., USA), $0.1 \% \mathrm{BSA}$, and insulin (if previously present) at $37^{\circ} \mathrm{C}$. At the end of this final 20-min incubation, the muscles were removed, trimmed of excess connective tissue, quickly frozen between aluminum blocks cooled with liquid nitrogen, and weighed. These muscles were dissolved in $0.5 \mathrm{ml} 0.5 \mathrm{~N} \mathrm{NaOH}, 5 \mathrm{ml}$ scintillation cocktail was added, and the specific intracellular accumulation of 2-deoxyglucose was determined as described previously [17, 18]. 


\section{CardioRenal \\ Medicine}

\begin{tabular}{l|l}
\hline Cardiorenal Med 2011;1:31-44 \\
\hline DOI: 10.1159/000322826 & $\begin{array}{l}\text { @ 2011 S. Karger AG, Basel } \\
\text { www.karger.com/crm }\end{array}$ \\
Published online: January 17, 2011 &
\end{tabular}

Lindborg et al.: Chronic CB1R Antagonism and Insulin Action

Assessment of Signaling Factor Functionality

From the remaining soleus muscle from each animal, two strips were prepared and incubated as described above. After a 60-min incubation in the absence and presence of insulin, the muscle strips were trimmed of excess connective tissue and frozen between aluminum blocks cooled with liquid nitrogen. Frozen tissues were homogenized in $8 \times$ volume of ice-cold lysis buffer $(50 \mathrm{mmol} / \mathrm{l} \mathrm{HEPES})$. Homogenates were incubated on ice for $20 \mathrm{~min}$ and then centrifuged at $13,000 \mathrm{~g}$ for $20 \mathrm{~min}$ at $4^{\circ} \mathrm{C}$. Total protein concentration was determined using the BCA method (Sigma Chemical). Equal amounts of total protein were separated by SDS-PAGE on $7.5,10$, or $12 \%$ polyacrylamide gels and transferred to nitrocellulose membranes. To determine protein expression and functionality of insulin-dependent and insulin-independent signaling factors, blots were incubated with commercially available antibodies against the signaling protein and the phosphorylated form of the protein. For the insulin-dependent signaling pathways, the following antibodies were used: glycogen synthase kinase (GSK) $3 \alpha / \beta$ (Upstate Biotechnology, Lake Placid, N.Y., USA) and phospho-GSK3 $\alpha / \beta$ Ser $^{21 / 9}$, protein kinase B (Akt) and phospho-Akt Ser ${ }^{473}$ (all Cell Signaling Technology, Beverly, Mass. USA). Additional signaling factors assessed were 5'-AMP-dependent protein kinase $\alpha(\mathrm{AMPK} \alpha)$, phospho-AMPK $\alpha \mathrm{Thr}^{172}$, p38 mitogen-activated protein kinase (MAPK) and phospho-p38 MAPK Thr ${ }^{180} / \mathrm{Tyr}^{182}$ (all Cell Signaling). After incubation with horseradish peroxidaseconjugated secondary antibodies, proteins were visualized by enhanced chemiluminescence using the ChemiDoc system (Bio-Rad, Hercules, Calif., USA). Band intensities were quantified using Quantity One software (Bio-Rad).

\section{Statistical Analysis}

All values are expressed as means \pm SE. Differences between two group means were determined using an unpaired Student's $t$ test. When comparing more than two group means, data were analyzed by one-way ANOVA with a post hoc Dunnett or Bonferroni test using SPSS software (version 17.0; SPSS, Chicago, Ill., USA). A level of $\mathrm{p}<0.05$ was set for statistical significance.

\section{Results}

\section{Effects of Chronic CB1R Antagonism on Food Consumption and Body Weight}

CB1R antagonism with $10 \mathrm{mg} / \mathrm{kg}$ SR141716 significantly $(\mathrm{p}<0.05)$ decreased food consumption in both the lean (64\%) and obese (31\%) animals $24 \mathrm{~h}$ after initiation of the treatment compared to controls allowed to eat ad libitum (fig. 1a, b). The SR141716-treated animals continued to consume significantly less chow than the ad libitum-fed controls until day 10 for the lean animals and day 14 for the obese animals. Body weight was also significantly reduced in the SR141716-treated animals compared to the ad libitum-fed control group by day $5(7 \%)$ for the lean animals and by day $6(8 \%)$ for the obese animals (fig. 1c, d). This reduction in body weight was maintained throughout the remainder of the study. There were no significant differences in food consumption and body weight between the SR141716treated group and the pair-fed control group in either phenotype.

Visceral fat mass was slightly less $(\sim 0.5 \mathrm{~g}$ or $12 \%)$ in the lean pair-fed group compared to the lean ad libitum-fed group (fig. 1e), with the largest decrease observed in the chronically SR141716-treated lean Zucker rats compared to both the lean ad libitum-fed group $(\sim 2.5 \mathrm{~g}$ or $59 \%)$ and the lean pair-fed control group ( $\sim 2.0 \mathrm{~g}$ or $54 \%)$. Moreover, compared to the obese ad libitum-fed group, visceral fat mass was decreased by pair feeding ( $\sim 9$ g or $21 \%)$ and slightly more by SR141716 treatment in the obese Zucker rats ( $\sim 10 \mathrm{~g}$ or $23 \%$; fig. 1f).

\section{Glucose Tolerance and Insulin Sensitivity following Chronic CB1R Antagonism}

Fasting plasma glucose levels were significantly decreased in lean pair-fed and SR141716treated animals compared to lean ad libitum-fed controls (fig. 2a), being associated with significantly elevated fasting insulin levels in both the lean pair-fed control and lean SR141716treated groups (fig. 2b). While fasting plasma insulin and glucose levels were not altered in 


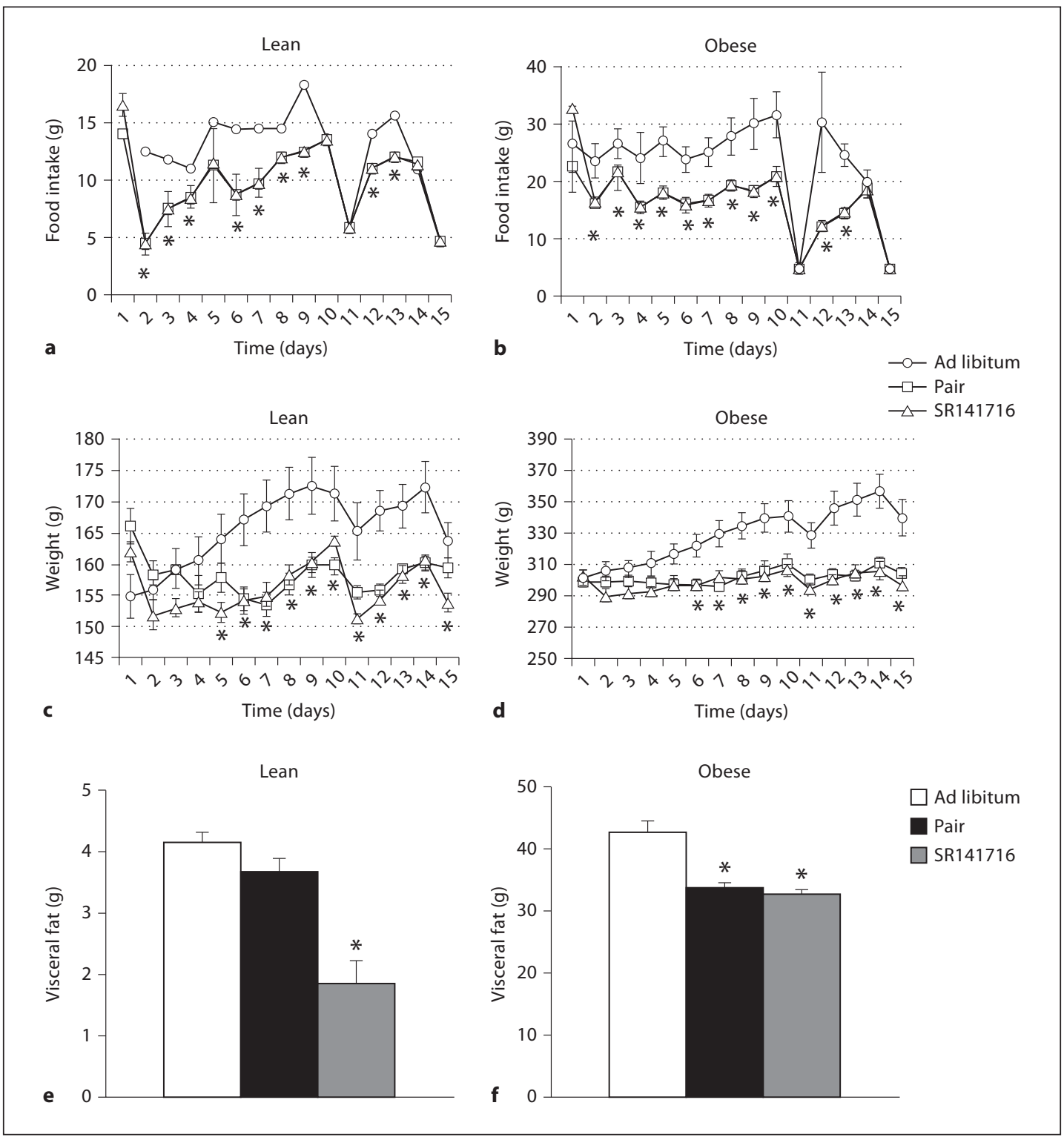

Fig. 1. Food consumption (a, b), body weight (c, d), and final visceral fat mass $(\mathbf{e}, \mathbf{f})$ of lean $(\mathbf{a}, \mathbf{c}, \mathbf{e})$ and obese Zucker rats $(\mathbf{b}, \mathbf{d}, \mathbf{f})$ during chronic treatment with SR141716. Values for food consumption are means \pm SE of chow consumed during the previous 24-hour period. Body weight and final visceral fat mass values are the means \pm SE for 4 animals per group. ${ }^{*} \mathrm{p}<0.05$, SR141716-treated group or pair-fed group vs. ad libitum-fed group (analyzed by one-way ANOVA with a Bonferroni post hoc test).

obese pair-fed and SR141716-treated animals compared to the obese controls (fig. 2d), there was a trend to decreased fasting plasma insulin levels in these two groups (fig. 2e). In both lean and obese animals, fasting plasma FFA levels were significantly reduced in the respective ad libitum-fed animals (fig. 2c, f), being further reduced by CB1R antagonism.

During the OGTT, the glucose excursions over the first $30 \mathrm{~min}$ in the lean pair-fed and SR141716-treated groups were significantly less compared to the lean ad libitum-fed controls, whereas these values did not differ among lean groups at 60 and $120 \mathrm{~min}$ (fig. 3a). The glucose area under the curve (AUC) during the OGTT was significantly decreased in the 


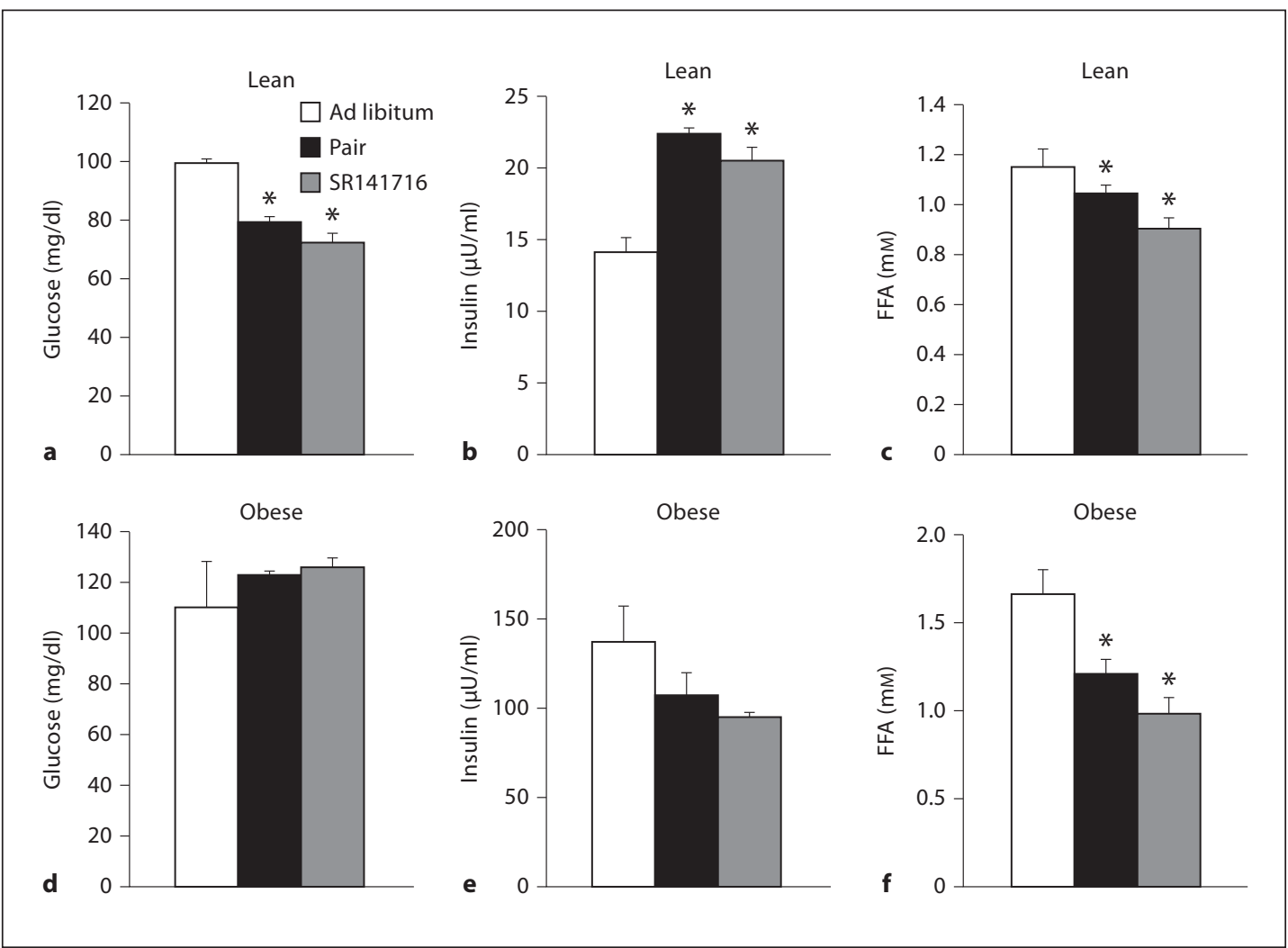

Fig. 2. Fasting plasma glucose (a, d), insulin (b, e), and FFA (c, f) in lean (a-c) and obese Zucker rats (d-f) after chronic treatment with SR141716. Values are means \pm SE for 4 animals per group. ${ }^{*} \mathrm{p}<0.05 \mathrm{vs}$. ad libitum-fed group (analyzed by one-way ANOVA, with a Dunnett post hoc test).

lean SR141716-treated group compared to the lean ad libitum-fed control group (fig. 3c). In the lean pair-fed and lean SR141716-treated groups, first-phase insulin secretion was decreased compared to the lean ad libitum-fed control group (fig. 3b). Moreover, this peak insulin value during the OGTT was significantly lower in the lean SR141716-treated group compared to the lean pair-fed group at the 60- and 120-min time points. Consequently, the insulin AUC in the lean pair-fed group was greater compared to the AUC of both the lean ad libitum-fed and the SR141716-treated groups (fig. 3d). Likewise, the glucose-insulin index (an inverse measure of insulin sensitivity [19]) was significantly increased in the lean pair-fed group compared to the lean ad libitum-fed control group (fig. 3e), indicating that this particular dietary manipulation leads to whole-body insulin resistance. Importantly, however, this increase in insulin resistance was ablated by SR141716 treatment in the lean animals.

In the obese Zucker rats, the excursion of blood glucose during the OGTT was not altered by reduced food consumption or chronic CB1R antagonism (fig. 3f, h). However, the excursion of insulin levels was reduced with pair feeding and was markedly and significantly diminished further with SR141716 treatment in the obese animals (fig. 3g, i). The glucoseinsulin index was significantly decreased in the obese group treated chronically with SR141716 compared to the obese ad libitum-fed group (fig. 3j), reflecting a significant enhancement of whole-body insulin sensitivity induced by the chronic CB1R antagonism in these obese animals. 


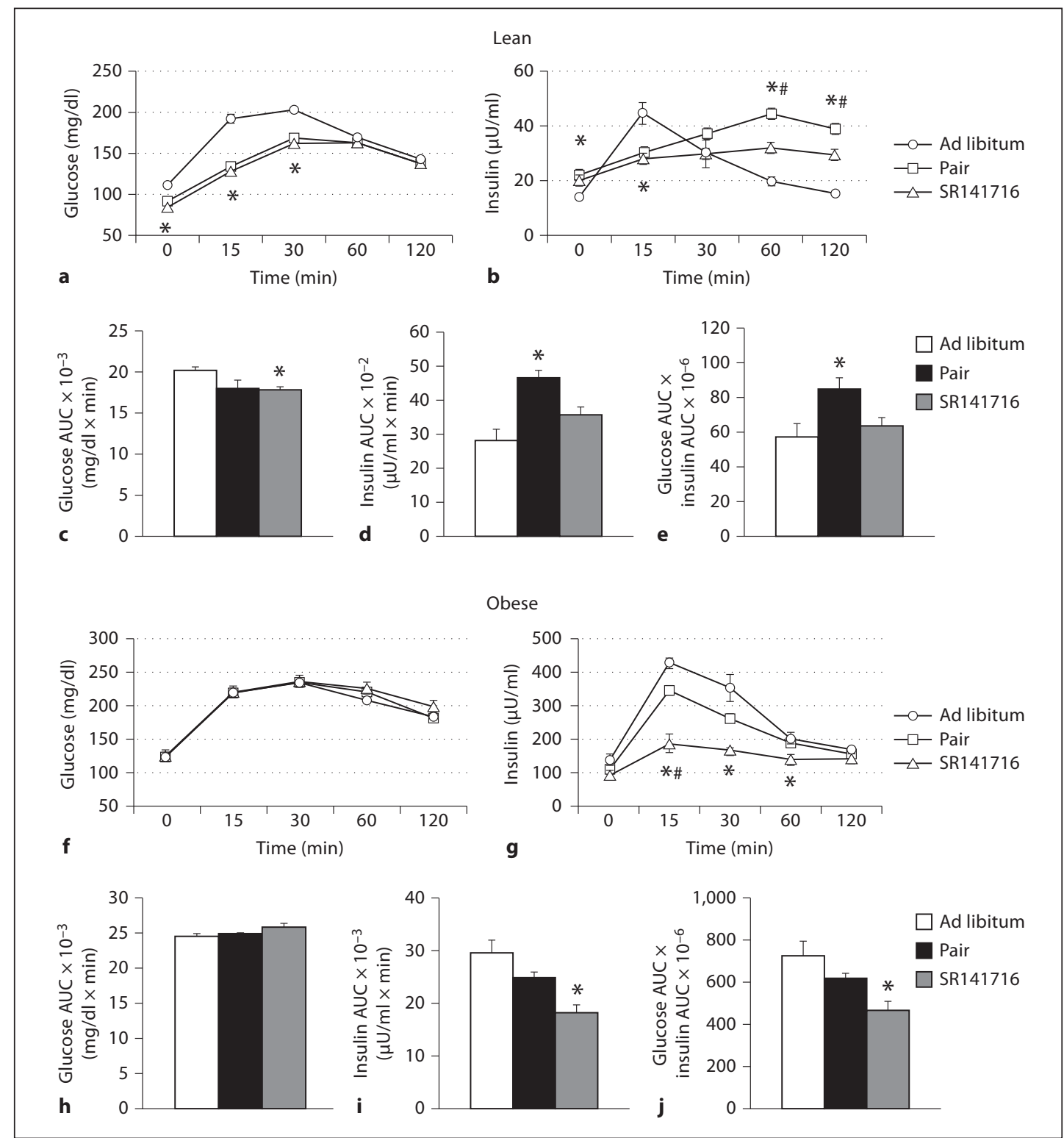

Fig. 3. Glucose tolerance (a, c, f, h) and insulin sensitivity $(\mathbf{b}, \mathbf{d}, \mathbf{g}$, i) in lean (a-e) and obese Zucker rats $(\mathbf{f}-\mathbf{j})$ after chronic treatment with SR141716. Glucose and insulin responses were assessed during an OGTT $(\mathbf{a}, \mathbf{b}, \mathbf{f}, \mathbf{g})$, and total AUC were calculated $(\mathbf{c}, \mathbf{d}, \mathbf{h}, \mathbf{i})$. The glucose-insulin index, inversely related to insulin sensitivity, was calculated as the product of the glucose and insulin AUC $(\mathbf{e}, \mathbf{j})$. Values are means $\pm \operatorname{SE}$ for 4 animals per group. ${ }^{*} \mathrm{p}<0.05$, SR141716-treated group vs. ad libitum-fed group; ${ }^{*} \mathrm{p}<0.05$, SR141716treated group vs. pair-fed group (analyzed by one-way ANOVA, with a Dunnett post hoc test).

\section{Effects of Chronic SR141716 Treatment on Soleus Muscle Glucose Transport}

There was no alteration in the basal glucose transport activity in the soleus muscle of either the lean or obese Zucker rats with pair feeding (fig. 4a, c). There was a small, but significant, decrease in basal glucose transport in the lean SR141716-treated group compared to the lean ad libitum-fed control group; this difference was not observed in the obese animals. Importantly, insulin-stimulated glucose transport activity was significantly increased in the soleus muscle following chronic CB1R antagonism in both the lean and obese groups (fig. 4b, d). 


\section{CardioRenal Medicine}

\begin{tabular}{l|l}
\hline Cardiorenal Med 2011;1:31-44 \\
\hline DOI: 10.1159/000322826 & $\begin{array}{l}\text { @ 2011 S. Karger AG, Basel } \\
\text { www.karger.com/crm }\end{array}$ \\
\hline
\end{tabular}

Lindborg et al.: Chronic CB1R Antagonism and Insulin Action
Fig. 4. Effects of chronic SR141716 treatment on glucose transport activity in isolated soleus muscles of lean (a, b) and obese Zucker rats (c, d). Glucose transport activity, assessed by 2-deoxyglucose (DG) uptake, was determined in the absence $(\mathbf{a}, \mathbf{c})$ or presence $(\mathbf{b}, \mathbf{d})$ of insulin $(5 \mathrm{mU} /$ $\mathrm{ml})$. Values are means \pm SE for 4 muscles per group. ${ }^{*} \mathrm{p}<0.05$ vs. ad libitum-fed group (analyzed by one-way ANOVA, with a Dunnett post hoc test).

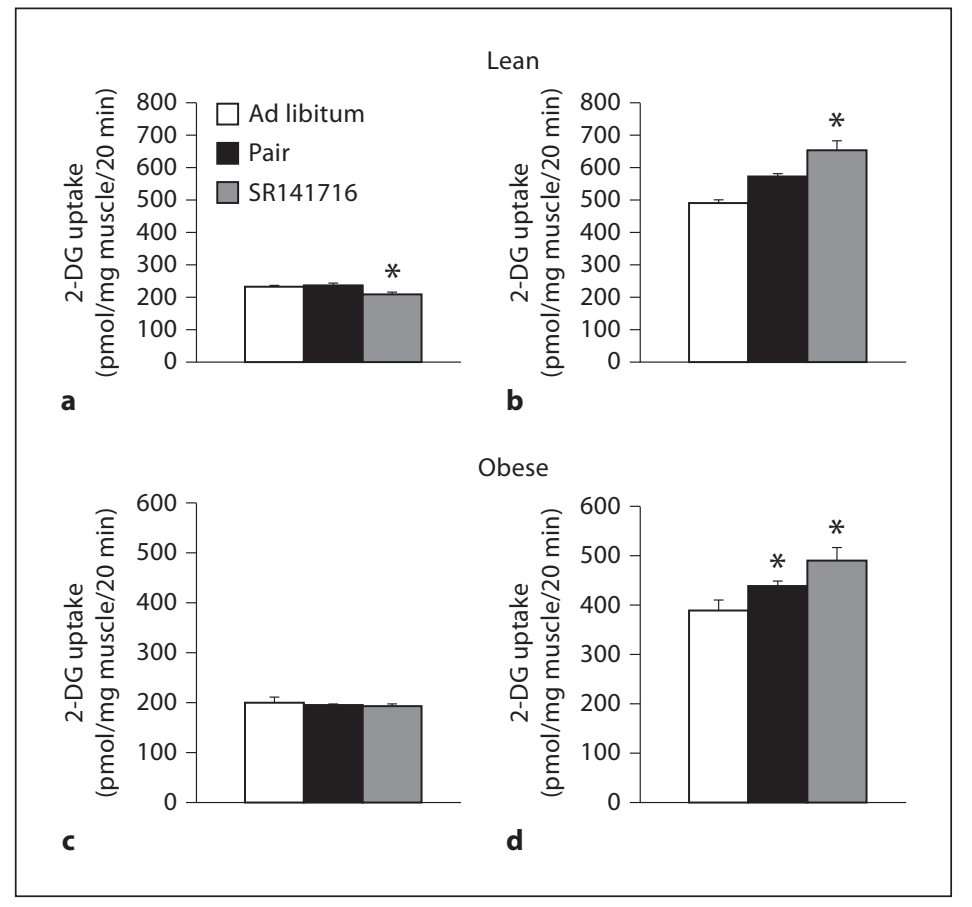

\section{Regulation of Signaling Elements Associated with Glucose Transport after Chronic SR141716 Treatment}

This increase in insulin-stimulated glucose transport activity in the soleus muscle of the lean and obese animals treated chronically with SR141716 (fig. 4) was not associated with altered functionality of key glucose transport signaling proteins (fig. 5). Basal and insulinstimulated phosphorylation of Akt $\left(\operatorname{Ser}^{473}\right)$, GSK3 $\beta$ ( $\left.\operatorname{Ser}^{9}\right)$, as well as the phosphorylation states of AMPK $\alpha\left(\mathrm{Thr}^{172}\right)$ and $\mathrm{p} 38 \mathrm{MAPK}\left(\mathrm{Thr}^{180} / \mathrm{Tyr}^{182}\right)$, did not differ among the groups within the lean or obese phenotypes.

Chronic treatment with SR141716 did not alter Akt Ser ${ }^{473}$ phosphorylation in vivo in the liver or plantaris of lean and obese Zucker rats, whether expressed only as the absolute ratio of the phosphorylated protein and the total Akt protein or expressed relative to the fasting plasma insulin level in the animals (data not shown).

\section{Effect of Acute SR141716 Treatment on Glucose Tolerance and Skeletal-Muscle Glucose Transport Activity}

An acute (2-hour) in vivo treatment with SR141716 did not alter basal or insulin-stimulated glucose transport activity in the soleus of lean or obese Zucker rats (data not shown), nor did this acute treatment alter the glucose and insulin responses to a glucose challenge in lean animals (data not shown). Glucose tolerance was not altered in the obese animals by acute SR141716 treatment (fig. 6a, c). However, acute SR141716 treatment of the obese Zucker rats significantly $(\mathrm{p}<0.05)$ reduced insulin levels at the 60 - and 120 -min time points compared to the vehicle-treated obese animals (fig. $6 \mathrm{~b}$ ), which was associated with a diminished insulin AUC (fig. 6d). Despite the decreased insulin AUC in the obese group treated acutely with SR141716, there was only a modest, and statistically insignificant, improvement in whole-body insulin sensitivity, as measured by the glucose-insulin index (fig. 6e). 


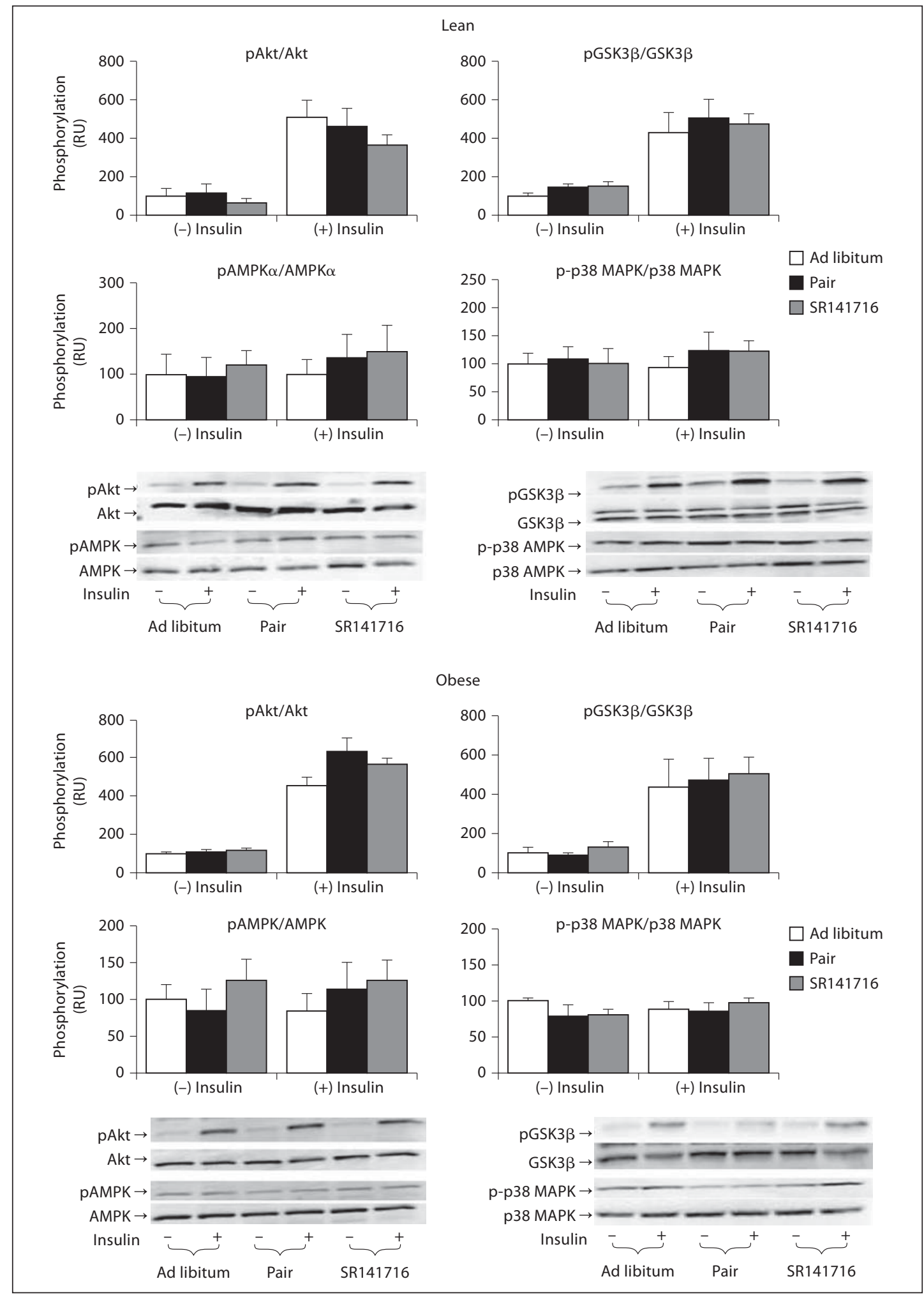

Fig. 5. Effect of chronic SR141716 treatment on signaling factors involved in the regulation of glucose transport activity in soleus muscles from lean and obese Zucker rats. Muscle strips were incubated in the absence or presence of insulin $(5 \mathrm{mU} / \mathrm{ml})$. Phosphorylation of Akt $\left(\mathrm{Ser}^{473}\right)$, GSK3 $\beta\left(\mathrm{Ser}^{9}\right)$, AMPK $\alpha\left(\mathrm{Thr}^{172}\right)$, and $\mathrm{p} 38$ MAPK $\left(\mathrm{Thr}^{180} / \mathrm{Tyr}^{182}\right)$ was expressed relative to total protein level of the signaling element. Values are means $\pm \mathrm{SE}$ for 4 muscles per group. $\mathrm{RU}=$ Relative units. 


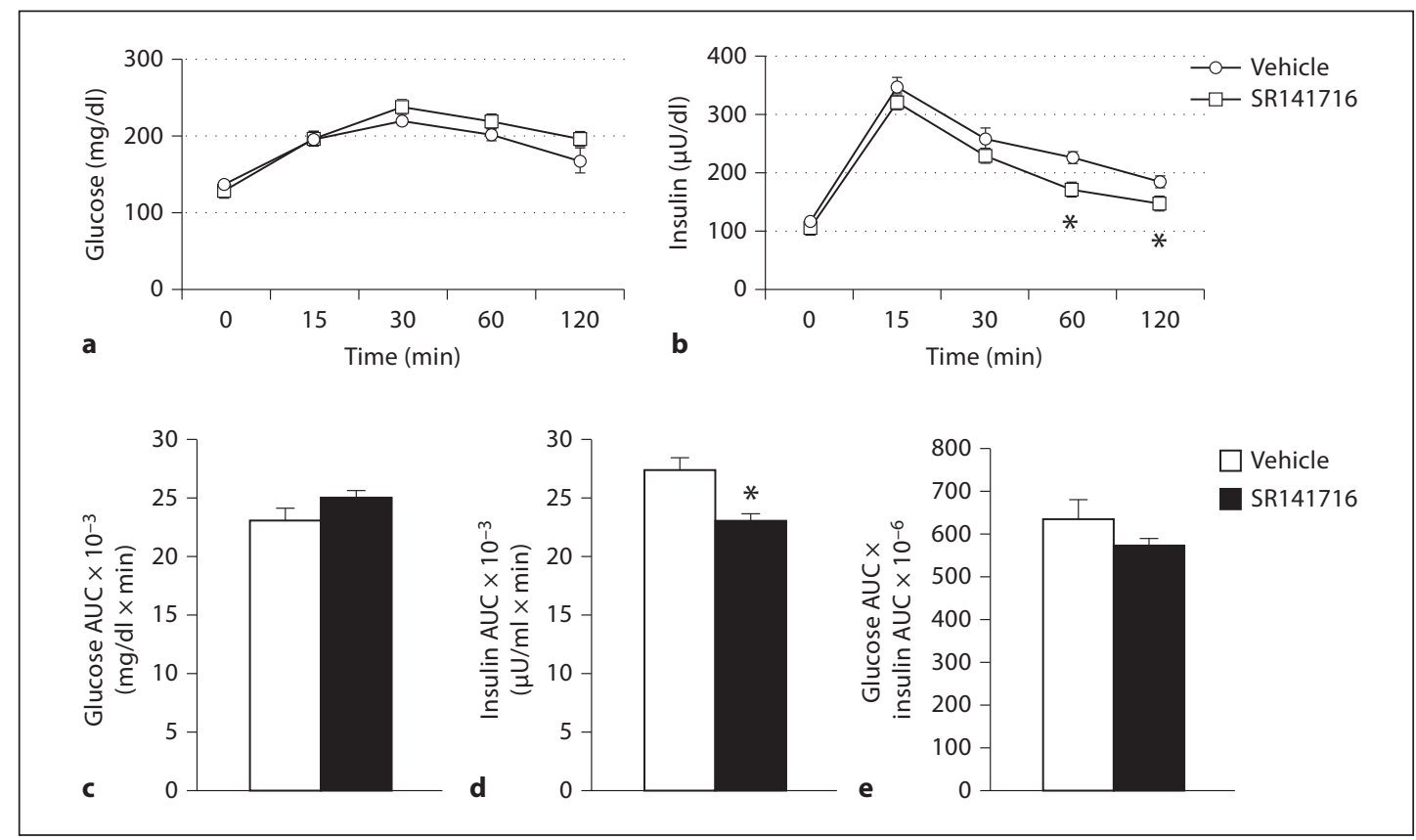

Fig. 6. Effect of acute treatment of obese Zucker rats with SR141716 on glucose (a) and insulin responses (b) during an OGTT; total AUC for glucose (c), insulin (d) and the glucose-insulin index (e) were also calculated. Data were analyzed as described in figure 3. Values are means \pm SE for 4 animals per group. ${ }^{*} \mathrm{p}<0.05$, vehicle-treated control group vs. acute SR141716-treated group (analyzed using an unpaired Student's t test).

\section{Discussion}

In the present study, we addressed for the first time the impact of chronic in vivo antagonism of the CB1R system using SR141716 on glucose tolerance, whole-body insulin sensitivity, and regulation of the insulin-dependent glucose transport system in skeletal muscles of both female insulin-sensitive, lean Zucker rats and female insulin-resistant, obese Zucker rats, the latter being a rodent model of the metabolic syndrome and pre-diabetes. A number of important findings have emerged from this study. We have demonstrated for the first time that, relative to pair-fed controls of the same phenotype, chronic CB1R antagonism with SR141716 improved whole-body insulin sensitivity in both lean (fig. 3e) and obese (fig. 3j) Zucker rats, but these improvements in insulin sensitivity were associated with different metabolic adaptations in the two phenotypes. In the lean animals, chronic CB1R antagonism was associated with a reduced glucose response during the OGTT (fig. 3a, c), while the insulin response was diminished compared to that of the corresponding pair-fed group (fig. 3b, d), leading to a lower glucose-insulin index (fig. 3e), indicative of enhanced peripheral insulin sensitivity. In contrast, in the obese animals, chronic SR141716 treatment had no absolute effect on glucose tolerance (fig. $3 f$, h), but was associated with a dramatically reduced insulin response to the glucose challenge (fig. $3 \mathrm{~g}$, i), resulting in a significant increase in insulin sensitivity compared to both ad libitum- and pair-fed controls (fig. 3j).

Our findings on the effects of chronic CB1R antagonism in the female obese Zucker rat on glucose and insulin responses to a glucose challenge differ in important ways from previous investigations. For example, a 15-day treatment with SR141716 (10 mg/kg) of male obese Zucker rats did induce reduced insulin secretion during an OGTT, but was associated with significantly higher glucose levels compared to vehicle-treated controls [12]. Interestingly, 


\section{CardioRenal \\ Medicine}

\begin{tabular}{l|l}
\hline Cardiorenal Med 2011;1:31-44 \\
\hline $\begin{array}{l}\text { DOI: 10.1159/000322826 } \\
\text { Published online: January 17, } 2011\end{array}$ & $\begin{array}{l}\text { @ } 2011 \text { S. Karger AG, Basel } \\
\text { www.karger.com/crm }\end{array}$ \\
\hline
\end{tabular}

Lindborg et al.: Chronic CB1R Antagonism and Insulin Action

after 1 month of treatment with SR141716 in these male obese animals, the insulin response during the OGTT remained diminished, but the glucose response was not different from vehicle-treated control values [12]. Our findings also contrast with a recent study in dietinduced obese rats, in which chronic treatment with SR141716 did not alter glucose levels or insulin secretion during a glucose tolerance test [11]. However, these diet-induced obese animals did display a significant increase in the rate of glucose disappearance during an insulin tolerance test [11], indicative of increased whole-body insulin sensitivity.

A further novel finding of the present investigation is the observation that chronic CB1R antagonism with SR141716 led to significant increases in insulin-stimulated glucose transport activity in isolated soleus muscle preparations from both lean and obese Zucker rats (fig. 4). Even though there was a significant increase in insulin-stimulated glucose transport activity in the soleus of both the lean and obese animals following chronic CB1R antagonism, we could not detect any alteration in the functionality of key signaling proteins involved in the regulation of insulin-dependent or insulin-independent glucose transport systems, including the phosphorylation of Akt, GSK3 $\beta$, AMPK $\alpha$, and p38 MAPK (fig. 5). This was not unexpected, considering our recent finding that direct CB1R antagonism with SR141716 in incubated soleus muscle strips of lean and obese Zucker rats improved insulin-stimulated glucose transport activity without altering the functionality of these key signaling proteins [20]. While several studies utilizing cultured muscle cells have shown altered phosphorylation of Akt, GSK3 $\beta$, and AMPK $\alpha$ with modulation of the CB1R system [21-25], these alterations have yet to be reproduced in vivo or in vitro with actual mammalian skeletal muscles. Moreover, we measured in vivo Ser ${ }^{473}$ phosphorylation of Akt in tissues such as the plantaris muscle and the liver (data not shown) and again could not demonstrate any change in this parameter with chronic CB1R antagonism, further indicating that Akt does not appear to be a direct target of CB1R in metabolically active tissues.

Elevated levels of plasma FFA are associated with insulin resistance and decreased glucose transport activity in skeletal muscles [26-28 and recently reviewed in ref. 29]. In the present study, we showed both a significant reduction in fasting plasma FFA (fig. 2) and an increase in insulin-stimulated glucose transport in soleus muscle preparations from lean and obese Zucker rats (fig. 4) that had been pair fed and, to a greater extent, treated chronically with the selective CB1R antagonist SR141716, compared to the ad libitum-fed controls. This finding is consistent with previous rodent studies that demonstrated a decrease in fasting plasma FFA levels $[15,16]$, as well as a reduction in circulating triglyceride levels $[11,13,24]$, following chronic CB1R antagonism. Investigations in human subjects have also shown a decrease in circulating triglycerides after 1 year of SR141716 treatment [14]. Whether a mechanistic connection between changes in circulating FFA levels and improvements in insulin action on glucose transport activity in skeletal muscles exists following chronic modulation of the CB1R system will require further investigation.

The present investigation can also shed light on the impact of transient reductions in caloric intake by lean and obese rats on whole-body and skeletal-muscle insulin action and glucose disposal. In both lean and obese animals, the initial caloric restriction was quite dramatic (31-64\% reduction after $24 \mathrm{~h}$ ), but slowly returned toward ad libitum-fed control levels by the end of the 2 -week period of the study (fig. 1). In lean animals, this transient caloric restriction was associated with a reduction in fasting plasma glucose and FFA (fig. 2), and improved glucose tolerance (fig. 3), but with an increase in fasting plasma insulin (fig. 2), an exaggerated insulin excursion and a worsening of whole-body insulin sensitivity (fig. 3), and no change in insulin-stimulated glucose transport (fig. 4) or insulin signaling (including Akt phosphorylation) in skeletal muscles (fig. 5). This latter observation contrasts with results of investigations on the impact of short-term, consistent caloric restriction (40\% reduction for 20 days) in lean rodents, which have demonstrated an increase in insulin-stimulated glucose 


\section{CardioRenal \\ Medicine}

\begin{tabular}{l|l}
\hline Cardiorenal Med 2011;1:31-44 \\
\hline $\begin{array}{l}\text { DOI: 10.1159/000322826 } \\
\text { Published online: January 17, } 2011\end{array}$ & $\begin{array}{l}\text { @ } 2011 \text { S. Karger AG, Basel } \\
\text { www.karger.com/crm }\end{array}$ \\
\hline
\end{tabular}

Lindborg et al.: Chronic CB1R Antagonism and Insulin Action

transport activity in skeletal muscles $[30,31]$ associated with enhanced Akt phosphorylation $[31,32]$. These findings indicate that the benefits of caloric restriction in a lean phenotype appear to be dependent on the regimen being continuous, rather than transient, in nature. Interestingly, the transient caloric restriction in the obese animals was associated with decreased fasting plasma insulin and FFA (fig. 2), small improvements in whole-body insulin sensitivity (fig. 3), and insulin-stimulated glucose transport activity in skeletal muscles (fig. 4), but again no change in muscle insulin signaling (fig. 5).

The only significant adaptation elicited by acute treatment of the obese Zucker rats with SR141716 was a small reduction in the insulin response to a glucose challenge (fig. 6). This acute SR141716-induced reduction in the insulin AUC (17\%) was much less robust than that brought about by chronic SR141716 treatment of these obese animals (39\%; fig. 3). The acute reduction in insulin secretion was accompanied by a slight, but statistically insignificant, decrease in glucose tolerance, and was not associated with any significant change in wholebody insulin sensitivity. Acute treatment of lean Zucker rats with SR141716 did not modulate any of the metabolic variables measured. This latter finding contrasts with a previous study in which acute CB1R antagonism with AM251 in lean male Wistar rats improved glucose tolerance [10]. Taken together, these data provide evidence that the metabolic effects of chronic SR141716 treatment of lean and obese Zucker rats are not due to the acute actions of the CB1R antagonist, but rather are associated with the cumulative effects of chronic CB1R antagonism.

In conclusion, it is clear that our understanding of the impact of chronic CB1R antagonism on peripheral, metabolically active tissues continues to increase. Results from the present study, as well as from several others in the literature, support the concept that the endocannabinoid system is an important component in the normal regulation of metabolic parameters $[1,7,33,34]$. Obesity is known to cause dysregulation of the endocannabinoid system $[35,36]$, leading to an elevation of circulating endogenous cannabinoid levels, and activation of the endocannabinoid system has been linked to decreased glucose tolerance [10] and insulin resistance in the whole body [37] and skeletal muscles [20]. The present investigation has demonstrated that chronic antagonism of the CB1R with SR141716 is associated with improved glucose tolerance, enhanced whole-body insulin sensitivity, a more favorable lipid profile, and improved insulin-dependent glucose transport activity in skeletal muscles, in both insulin-sensitive lean Zucker rats and insulin-resistant obese Zucker rats. The endocannabinoid system should continue to be an important target in the design of interventions for improving insulin action in conditions of obesity-associated whole-body and skeletalmuscle insulin resistance.

\section{Disclosure Statement}

This study was supported by grant DK063967 (to E.J.H.) and training grant T32 HL07249 (to K.A.L.) from the National Institutes of Health.

\section{References}

1 Kakafika AI, Mikhailidis DP, Karagiannis A, Athyros VG: The role of endocannabinoid system blockade in the treatment of the metabolic syndrome. J Clin Pharmacol 2007;7:642-652.

2 Herling AW, Gossel M, Harschke G, Stengelin S, Kuhlmann J, Müller G, Schmoll D, Kramer W: CB1 receptor antagonist AVE1625 affects primarily metabolic parameters independently of reduced food intake in Wistar rats. Am J Physiol Endocrinol Metab 2007;93:E826-E832.

3 Matias I, Di Marzo V: Endocannabinoids and the control of energy balance. Trends Endocrinol Metab 2007;18:27-37. 


\section{CardioRenal Medicine}

\begin{tabular}{l|l}
\hline Cardiorenal Med 2011;1:31-44 \\
\hline DOI: $10.1159 / 000322826$ \\
Published online: January 17, 2011 & $\begin{array}{l}\text { @ 2011 S. Karger AG, Basel } \\
\text { www.karger.com/crm }\end{array}$ \\
\hline
\end{tabular}

Lindborg et al.: Chronic CB1R Antagonism and Insulin Action

-4 Nogueiras R, Veyrat-Durebex C, Suchanek PM, Klein M, Tschöp J, Caldwell C, Woods SC, Wittmann G, Watanabe M, Liposits Z, Fekete C, Reizes O, Rohner-Jeanrenaud F, Tschöp MH: Peripheral, but not central, CM1 antagonism provides food intake-independent metabolic benefits in diet-induced obese rats. Diabetes 2008;57:2977-2991.

-5 Di Marzo V, Goparaju SK, Wang L, Liu J, Bátkal S, Járai Z, Fezza F, Miura GI, Palmiter RD, Suguira T, Kunos G: Leptin-regulated endocannabinoids are involved in maintaining food intake. Nature 2001;410:822-825.

6 Vickers SP, Webster LJ, Wyatt A, Dourish CT, Kennett GA: Preferential effects of the cannabinoid CB1 receptor antagonist, SR141716, on food intake and body weight gain of obese (fa/fa) compared to lean Zucker rats. Psychopharmacology (Berl) 2003;167:103-111.

7 Scheen AJ, Paquot N: Inhibitors of cannabinoid receptors and glucose metabolism. Curr Opin Clin Nutr Metab Care 2008;11:505-511.

8 Cota D, Marsicano G, Tschöp M, Grübler Y, Flachskamm C, Schubert M, Auer D, Yassouridis A, Thöne-Reineke C, Ortmann S, Tomassoni F, Cervino C, Nisoli E, Linthorst AC, Pasquali R, Lutz B, Stalla GK, Pagotto U: The endogenous cannabinoid system affects energy balance via central orexigenic drive and peripheral lipogenesis. J Clin Invest 2003; 112:423-431.

-9 Liu YL, Connoley IP, Wilson CA, Stock MJ: Effects of the cannabinoid CB1 receptor antagonist SR141716 on oxygen consumption and soleus muscle glucose uptake in Lep ${ }^{\mathrm{ob}} / \mathrm{Lep}^{\mathrm{ob}}$ mice. Int J Obes 2005;29:183-187.

-10 Bermúdez-Siva FJ, Serran A, Diaz-Molina FJ, Sánchez Vera I, Juan Pico P, Nadal A, Fuentes E, Rodríguez de Fonseca F: Activation of cannabinoid CB1 receptors induces glucose intolerance in rats. Eur J Pharmacol 2006;531:282-284.

11 Cota D, Sandoval DA, Olivieri M, Prodi E, D’Alessio DA, Woods SC, Seeley RJ, Obici S: Food intake-independent effects of CB1 antagonism on glucose and lipid metabolism. Obesity 2009;17:1641-1645.

12 Duvivier VF, Delafoy-Plasse L, Delion V, Lechevalier P, Le Bail JC, Guillot E, Pruniaux MP, Galzin AM: Beneficial effect of a chronic treatment with rimonabant on pancreatic function and $\beta$-cell morphology in Zucker fatty rats. Eur J Pharmacol 2009;616:314-320.

13 Flamment M, Gueguen N, Wetterwald C, Simard G, Malthièry Y, Ducluzeau PH: Effects of the cannabinoid CB1 antagonist rimonabant on hepatic mitochondrial function in rats fed a high-fat diet. Am J Physiol Endocrinol Metab 2009;297:E1162-E1170.

14 Després JP, Ross R, Boka G, Alméras N, Lemieux I, ADAGIO-Lipids Investigators: Effect of rimonabant on the hightriglyceride/low-HDL-cholesterol dyslipidemia, intraabdominal adiposity, and liver fat: the ADAGIO-Lipids trial. Arterioscler Thromb Vasc Biol 2009;29:416-423.

15 Gary-Bobo M, Elachouri G, Gallas JF, Janiak P, Marini P, Ravinet-Trillou C, Chabbert M, Cruccioli N, Pfersdorff C, Roque C, Arnone M, Croci T, Soubrié P, Oury-Donat F, Maffrand JP, Scatton B, Lacheretz F, Le Fur G, Herbert JM, Bensaid M: Rimonabant reduces obesity-associated hepatic steatosis and features of metabolic syndrome in obese Zucker fa/fa rats. Hepatology 2007;46:122-129.

-16 Ravinet Trillou C, Arnone M, Delgorge C, Gonalons N, Keane P, Maffrand JP, Soubrié P: Anti-obesity effect of SR141716, a CB1 receptor antagonist, in diet-induced obese mice. Am J Physiol Regul Integr Comp Physiol 2003; 284:R345-R353.

$\checkmark 17$ Henriksen EJ, Halseth AE: Early alterations in soleus GLUT-4, glucose transport, and glycogen in voluntary running rats. J Appl Physiol 1994;76:1862-1867.

18 Hansen PA, Gulve ES, Holloszy JO: Suitability of 2-deoxyglucose for in vitro measurement of glucose transport activity in skeletal muscle. J Appl Physiol 1994;76:979-985.

19 Cortez MY, Torgan CE, Brozinick JT, Ivy JL: Insulin resistance of obese Zucker rats exercise trained at two different intensities. Am J Physiol Endocrinol Metab 1991;261:E613-E619.

20 Lindborg KA, Teachey MK, Jacob S, Henriksen EJ: Effects of in vitro antagonism of endocannabinoid-1 receptors on the glucose transport system in normal and insulin-resistant rat skeletal muscle. Diabetes Obes Metab 2010;12:722730 .

21 Cavuoto P, McAinch AJ, Hatzinikolas G, Cameron-Smith D, Wittert GA: Effects of cannabinoid receptors on skeletal muscle oxidative pathways. Mol Cell Endocrinol 2007;267:63-69.

22 Esposito I, Proto MC, Gazzerro P, Laezza C, Miele C, Alberobello AT, D’Esposito V, Beguinot F, Formisano P, Bifulco M: The cannabinoid CB1 receptor antagonist rimonabant stimulates 2-deoxyglucose uptake in skeletal muscle cells by regulating the expression of phosphatidylinositol-3-kinase. Mol Pharmacol 2008;74:1678-1686.

-23 Eckardt K, Sell H, Taube A, Koenen M, Platzbecker B, Cramer A, Horrighs A, Lehtonen M, Tennagels N, Eckel J: Cannabinoid type 1 receptors in human skeletal muscle cells participate in the negative crosstalk between fat and muscle. Diabetologia 2009;52:664-674.

-24 Watanabe T, Kubota N, Ohsugi M, Kubota T, Takamoto I, Iwabu M, Awazawa M, Katsuyama H, Hasegawa C, Tokuyama K, Moroi M, Sugi K, Yamauchi T, Noda T, Nagai R, Terauchi Y, Tobe K, Ueki K, Kadowaki T: Rimonabant ameliorates insulin resistance via both adiponectin-dependent and adiponectin-independent pathways. J Biol Chem 2009;284:1803-1812.

25 Lipina C, Stretton C, Hastings S, Hundal JS, Mackie K, Irving AJ, Hundal HS: Regulation of MAP kinase-directed mitogenic and protein kinase B-mediated signaling by cannabinoid receptor type 1 in skeletal muscle cells. Diabetes 2010;59:375-385.

26 Dresner A, Laurent D, Marcucci M, Griffin ME, Dufour S, Cline GW, Slezak LA, Andersen DK, Hundal RS, Rothman DL, Petersen KF, Shulman GI: Effects of free fatty acids on glucose transport and IRS-1-associated phosphatidylinositol 3-kinase activity. J Clin Invest 1999;103:253-259. 


\section{CardioRenal Medicine}

\begin{tabular}{l|l}
\hline Cardiorenal Med 2011;1:31-44 \\
\hline $\begin{array}{l}\text { DOI: 10.1159/000322826 } \\
\text { Published online: January 17, } 2011\end{array}$ & $\begin{array}{l}\text { @ 2011 S. Karger AG, Basel } \\
\text { www.karger.com/crm }\end{array}$ \\
\hline
\end{tabular}

Lindborg et al.: Chronic CB1R Antagonism and Insulin Action

27 Griffin ME, Marcucci MJ, Cline GW, Bell K, Barucci N, Lee D, Goodyear LJ, Kraegen EW, White MF, Shulman GI: Free fatty acid-induced insulin resistance is associated with activation of protein kinase $\mathrm{C}$ theta and alterations in the insulin signaling cascade. Diabetes 1999;48:1270-1274.

28 Yu C, Chen Y, Cline GW, Zhang D, Zong H, Wang Y, Bergeron R, Kim JK, Cushman SW, Cooney GJ, Atcheson B, White MF, Kraegen EW, Shulman GI: Mechanism by which fatty acids inhibit insulin activation of insulin receptor substrate-1 (IRS-1)-associated phosphatidylinositol 3-kinase activity in muscle. J Biol Chem 2002;277:50230-50236.

29 Taube A, Eckardt K, Eckel J: Role of lipid-derived mediators in skeletal muscle in insulin resistance. Am J Physiol Endocrinol Metab 2009;297:E1004-E1012.

-30 Cartee GD, Dean DJ: Glucose transport with brief dietary restriction: heterogenous responses in muscles. Am J Physiol Endocrinol Metab 1994;266:E946-E952.

-31 McCurdy CE, Davidson RT, Cartee GD: Calorie restriction increases the ratio of phosphatidylinositol 3-kinase catalytic to regulatory subunits in rat skeletal muscle. Am J Physiol Endocrinol Metab 2005;288:E996-E1001.

-32 McCurdy CE, Davidson RT, Cartee GD: Brief calorie restriction increases Akt2 phosphorylation in insulin-stimulated rat skeletal muscle. Am J Physiol Endocrinol Metab 2003;285:E693-E700.

-33 Xie S, Furjanic MA, Ferrara JJ, McAndrew NR, Ardino EL, Ngondara A, Bernstein Y, Thomas KJ, Kim E, Walker JM, Nagar S, Ward SJ, Raffa RB: The endocannabinoid system and rimonabant: a new drug with a novel mechanism of action involving cannabinoid CB1 receptor antagonism - or inverse agonism - as potential obesity treatment and other therapeutic use. J Clin Pharm Ther 2007;32:209-231.

34 de Kloet AD, Woods SC: Minireview: endocannabinoids and their receptors as targets for obesity therapy. Endocrinology 2009;150:2531-2536.

35 D'Eon TM, Pierce KA, Roix JJ, Tyler A, Chen H, Teixeira SR: The role of adipocyte insulin resistance in the pathogenesis of obesity-related elevations in endocannabinoids. Diabetes 2008;57:1262-1268.

-36 Engeli S, Böhnke J, Feldpausch M, Gorzelniak K, Janke J, Bátkai S, Pacher P, Harvey-White J, Luft FC, Sharma AM, Jordan J: Activation of the peripheral endocannabinoid system in human obesity. Diabetes 2008;54:2838-2843.

-37 Blüher M, Engeli S, Klöting N, Berndt J, Fasshauer M, Bátkai S, Pacher P, Schön MR, Jordan J, Stumvoll M: Dysregulation of the peripheral and adipose tissue endocannabinoid system in human abdominal obesity. Diabetes 2006;55: 3053-3060. 